\title{
Diffusion Potentials and Potassium Distribution across the Gallbladder Wall *
}

\author{
John M. Dietschy † and Edward W. Moore \\ (From the Evans Memorial Department of Clinical Research, Massachusetts Memorial Hos- \\ pitals, the Department of Medicine, Boston University School of Medicine, the Metabolic \\ Laboratories of the Medical Services, Lemuel Shattuck Hospital, Commonwealth of \\ Massachusetts, and the Department of Medicine, Tufts University School of \\ Medicine, Boston, Mass.)
}

During the process of concentration of bile by the gallbladder, water and electrolytes are absorbed, leaving behind bile acids, bilirubin pigment, and other substances to which the gallbladder epithelium is not permeable. It has recently been postulated (1) that this resorptive process depends upon a "neutral" ion pump in the gallbladder epithelium that transports sodium, anions, and water out of the bile into the blood. Hepatic bile is thus progressively converted from a solution in which the major ions are sodium, chloride, bicarbonate, and bile acid to concentrated gallbladder bile, which consists predominantly of sodium and bile acid ions. Bile remains isosmotic with the serum during this transformation in composition. Since the osmotic coefficient of sodium bile salt is, on the average, only about 0.45 (2), the total concentration of ions in concentrated bile must be about twice that of serum. Typically, whole bile sodium and bile acid concentrations are of the order of $300 \mathrm{mEq}$ per L each.

During this concentrating process, changes also occur in the levels of potassium, which increase from 4 to $5 \mathrm{mEq}$ per $\mathrm{L}$ in newly formed hepatic bile to 10 to $14 \mathrm{mEq}$ per $\mathrm{L}$ in concentrated gallbladder bile. This increase in potassium concentration has been assumed to be due to "secretion"

* Submitted for publication June 14, 1963; accepted April 2, 1964.

Supported in part by U. S. Public Health Service training grant 2A-5025 (C6) and by research grants A-3560 (C3) and AM-07417 from the National Institute of Arthritis and Metabolic Diseases.

This work appeared in abstract form in Clin. Res. 1963, 11, 182.

† Present address: Department of Medicine, University of Texas Southwestern Medical School, Dallas 35 , Texas. of potassium ions by the gallbladder epithelium or to a Donnan effect produced by the nondiffusible bile acid ions $(3,4)$. However, if a potential difference exists between the mucosal and serosal surface of the gallbladder and if potassium is freely diffusible across the epithelial membrane, then this ion would become distributed between the bile and the blood as predicted by the Nernst equation. The present studies were done to measure these potential differences and to demonstrate if they do indeed affect potassium distribution across the gallbladder epithelium.

\section{Methods}

Gallbladder preparations. Three types of rabbit gallbladder preparations were used: the isolated everted gallbladder, the isolated noneverted gallbladder, and the in vivo cannulated gallbladder. Adult male rabbits weighing 3.0 to $4.5 \mathrm{~kg}$ were anesthetized with 100 to $150 \mathrm{mg}$ of sodium pentobarbital administered slowly into an ear vein. The abdomen was opened, the cystic duct was clamped and cut, and the gallbladder was stripped upward from its bed on the liver with the aid of small scissors. The neck of the gallbladder was cut across just distal to where it joined the cystic duct, and the organ was immediately everted on a fine glass rod. It was then placed in a tray of Tyrode's solution at $37^{\circ} \mathrm{C}$ and secured on a tapered glass cannula with silk ligatures. The mucosal (outside) surface of the gallbladder could now be exposed to different experimental solutions by simply transferring the cannulated gallbladder from container to container. Solutions on the inner, or serosal surface, were changed by introducing a fine catheter down the glass cannula into the serosal compartment and aspirating and refilling with a small syringe. The mucosal and serosal fluid levels were maintained at equal levels. Care was taken not to overdistend the gallbladder, since this appeared to change the permeability characteristics of the epithelial membrane.

Studies were also done on gallbladders that were handled in an identical manner except that they were not everted. This made it possible to expose the inner 


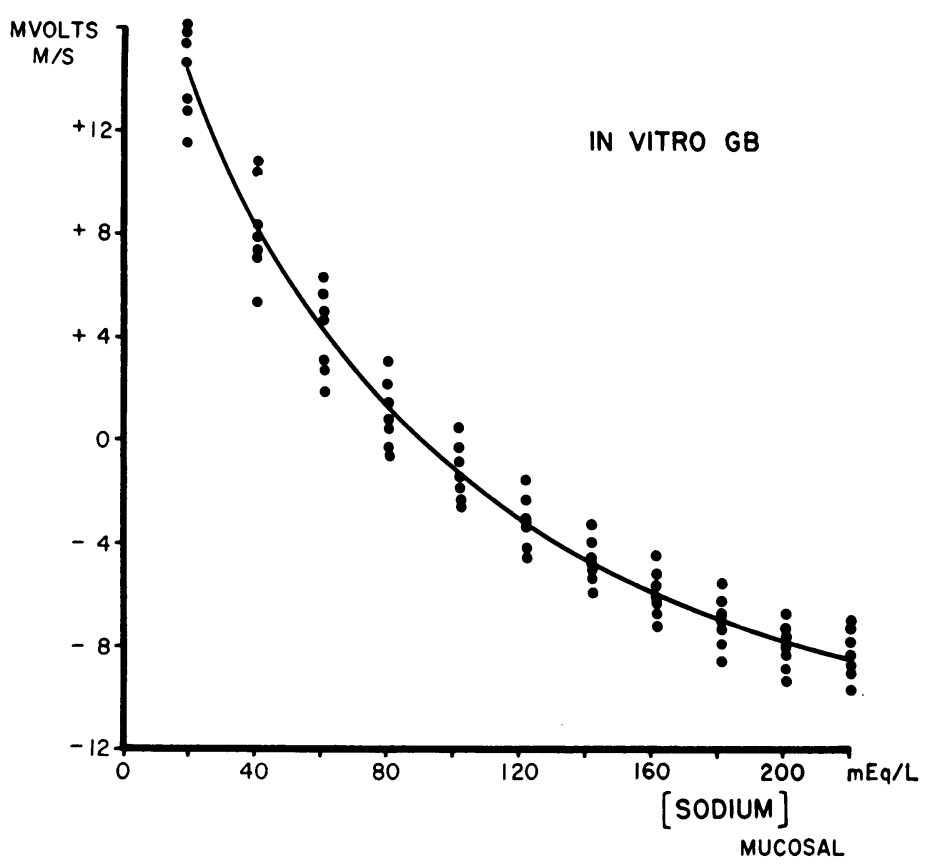

Fig. 1. Potential differences across the WAll OF SEven EVERTED GALLBLADDERS WHEN THE SEROSA WAS BATHED IN TYRODE'S SOLUTION AND THE MUCOSA WAS EXPOSED TO SULFATE TEST SOLUTIONS With SODIUM CONCENTRATIONS VARYiNG From 20 To 220 MEQ PER L. The solid line represents the mean values.

or mucosal surface to small volumes $(0.75$ to $1.50 \mathrm{ml})$ of such test solutions as whole bile. Systematic determination of permeability constants for several ions in both the everted and noneverted gallbladders gave identical results, indicating that eversion did not alter the permeability characteristics of the epithelial surface. All in vitro studies were done in a constant temperature water bath at $37^{\circ} \mathrm{C}$.

In vivo preparations were made in rabbits maintained on intravenous sodium pentobarbital anesthesia. From 10 to $50 \mathrm{mg}$ of the barbiturate was administered into an ear vein each hour depending upon the apparent level of anesthesia in the individual animal as judged by its respirations and corneal reflex. Animals could be maintained for up to 4 hours in this manner. After opening the abdomen the cystic duct was isolated from the cystic artery and tied. A small incision was made distal to the tie, and a polyethylene catheter was inserted into the apex of the gallbladder until it protruded 1 to $2 \mathrm{~mm}$ into the lumen. Silk ligatures were used to secure the catheter in place. The mucosal surface could then be washed and exposed to different test solutions, and the catheter could be clamped to leave the test solution in the gallbladder for varying periods of time.

Solutions. The in vitro gallbladders were prepared in modified Tyrode's solution gassed with $95 \% \quad \mathrm{O}_{2}$ and $5 \%$ $\mathrm{CO}_{2}$. The composition of this solution in millimoles per liter is $\mathrm{NaCl}, 137 ; \mathrm{NaHCO}_{3}, 12 ; \mathrm{KCl}, 2.9 ; \mathrm{CaCl}_{2}, 1.8$; $\mathrm{MgCl}_{2}, 0.5 ; \mathrm{NaH}_{2} \mathrm{PO}_{4}, 0.4$; and glucose, 11.1. It had an osmolality of $292 \pm 5 \mathrm{mOsm}$ per $\mathrm{L}$ and a $\mathrm{pH}$ of $7.4 \pm$ 0.2 after gassing. Tyrode's solution was also used as the serosal bathing fluid in both the everted and noneverted in vitro gallbladder preparations.

Two types of mucosal solutions were used, a sulfatecontaining test solution and rabbit whole bile. Since concentrated bile is composed mainly of the sodium salt of a nondiffusible anion (bile acid), this chemical situation was approximated with solutions containing the sodium salt of another essentially nondiffusible anion, sulfate. The sulfate test solutions contained $\mathrm{Na}_{2} \mathrm{SO}_{4}$ in concentrations varying from 20 to $220 \mathrm{mEq}$ per L and $\mathrm{K}_{2} \mathrm{SO}_{4}$ at a constant concentration of $3.5 \mathrm{mEq}$ per $\mathrm{L}$. Mannitol was added to give each test solution a final osmolality of $295 \pm 5 \mathrm{mOsm}$ per $\mathrm{L}$, which equals the mean osmolality of rabbit serum. Hereafter, the expression "sulfate test solution" always refers to this isosmotic mixture of sodium and potassium sulfate. Bile samples of varying ionic composition were obtained by aspiration from the gallbladders of rabbits fasted for 6 to 30 hours. These samples were frozen at $-15^{\circ} \mathrm{C}$ until used.

Potential measurements. Polyethylene catheters (i.d., 0.034 inches) were filled with a $3 \%$ agar, saturated $\mathrm{KCl}$ solution. In the in vitro experiments one such salt bridge was placed in the outer solution, and another was inserted down the glass cannula into the inner solution. In the in vivo preparations one bridge was inserted into the gallbladder cannula to make contact with the mucosal solution, and the other was applied directly to the serosa of 


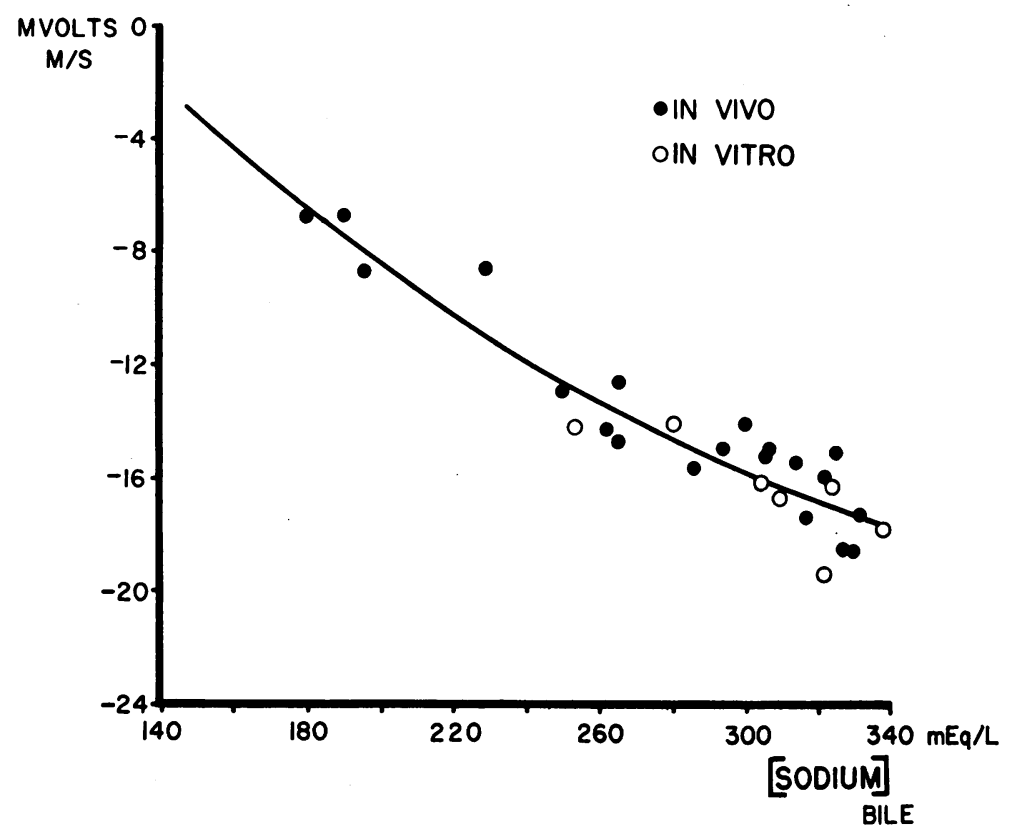

Fig. 2. Potential differences across the gallbladder wall plotted AS A FUNCTION OF THE BILE SAMPLE SODIUM CONCENTRATION ON THE MUCOSAL SURFACE. The open circles represent data obtained in noneverted, in vitro gallbladders where the serosa was bathed in Tyrode's solution. The solid circles are for bile samples placed in the in vivo gallbladder. The solid line represents the approximate mean of these points.

the gallbladder. To avoid damage to the gallbladder preparations from potassium diffusion out of the bridges, the $\mathrm{KCl}$-filled catheters were left in place only long enough to obtain reliable voltage measurements; usually less than 1 minute was required to reach a stable reading. The salt bridges led to two balanced calomel cells, which were connected to a high impedance volt meter. ${ }^{1}$ Appropriate corrections were made for day to day electrical imbalance in the system $( \pm 0.5 \mathrm{mv})$. The sign of the potentials is always expressed in terms of the mucosal voltage with respect to the serosa. Variation from the mean values is given as $\pm 2 \mathrm{SD}$ ( $95 \%$ confidence limit). Activity determinations. The activities of sodium and potassium in various mixed solutions were measured by means of sodium and potassium specific glass electrodes, respectively. ${ }^{2}$ The electrodes used are described in detail elsewhere $(2,5)$. Activity coefficients $(\gamma)$ were calculated by dividing the activity of a particular ion, as determined by the appropriate electrode, by the concentration of that ion, as determined by flame photometry.

\section{Results}

Potentials in the in vitro gallbladder. With the everted gallbladder the serosal surface was bathed in Tyrode's solution while the mucosal surface

1 Radiometer, Copenhagen, Denmark.

2 Obtained from Orion Research, Inc., Cambridge, Mass. was exposed to sulfate test solutions with sodium concentrations varying from 20 to $220 \mathrm{mEq}$ per L. The potentials that developed in seven such gallbladder preparations are plotted in Figure 1 as a function of the sodium concentration in the mucosal test solution. At a mucosal sodium concentration of $20 \mathrm{mEq}$ per $\mathrm{L}$ the mucosa was $14.3 \pm 3.6 \mathrm{mv}$ positive to the serosa. The voltage dropped to $-7.9 \pm 2.4 \mathrm{mv}$ as the mucosal sodium level was raised to $220 \mathrm{mEq}$ per L. Similar potentials were obtained in three gallbladders that were immersed in Tyrode's solution containing iodoacetate, $5 \times 10^{-5} \mathrm{M}$, for 10 minutes before exposure to the test solutions.

Potential differences were also measured when the mucosa of the noneverted, in vitro gallbladder was exposed to rabbit whole bile. In these studies Tyrode's solution was again the serosal fluid. In Figure 2 the potential differences that developed across the wall of seven such preparations are shown as open circles and plotted as a function of the bile sodium concentration on the mucosal surface. These values varied from -14.2 to $-19.0 \mathrm{mv}$ for bile samples with sodium con- 


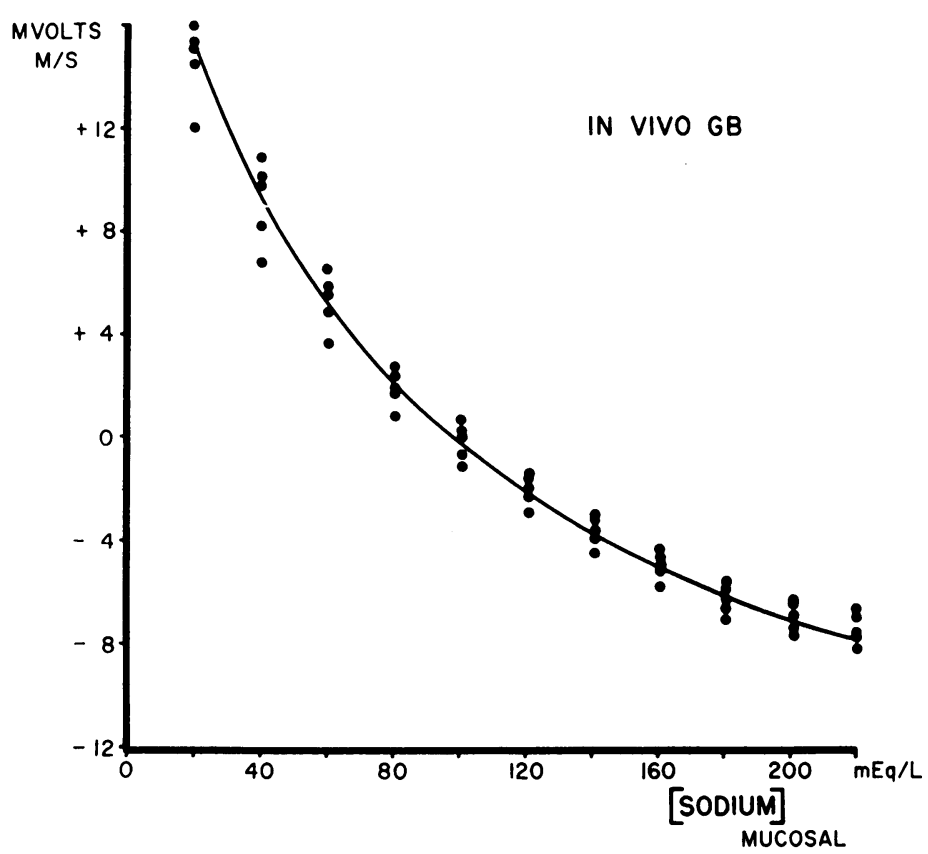

Fig. 3. Potential differences across the wall of five in vivo GALLBLADDERS THAT WERE SEQUENTIALly FILLED WITH SULFATE TEST SOLUTIONS WITH SODIUM CONCENTRATIONS VARYING FROM 20 TO 220 ${ }_{M} E_{Q}$ PER L. The solid line represents the mean values.

centrations that varied from 250 to $335 \mathrm{mEq}$ per L.

Potentials in the in vivo gallbladder. To demonstrate that similar potentials exist in the in vivo gallbladder, sulfate test solutions and whole bile samples were introduced into gallbladders left in situ, and potential measurements taken. In this experimental preparation the animal's blood perfused the serosal surface of the epithelial membrane. Figure 3 illustrates the magnitude of the potentials that developed in five in vivo gallbladders which were sequentially filled with a series of sulfate test solutions of varying sodium concentrations. These potentials fell from $+14.6 \pm 3.2$ to $-7.4 \pm 1.4 \mathrm{mv}$ as the mucosal sodium concentration was progressively increased from 20 to $220 \mathrm{mEq}$ per $\mathrm{L}$. When the in vivo gallbladder was filled with whole bile, potentials developed between the mucosa and serosa that varied from -6.5 to $-18.0 \mathrm{mv}$ as the sodium concentration ranged from 180 to $330 \mathrm{mEq}$ per $\mathrm{L}$ in the various bile samples. The data for 20 such experiments are plotted as the solid circles in Figure 2.

Thus, when either sulfate test solution or whole bile was placed in the functioning gallbladder in vivo, potential differences developed between the mucosal and serosal surfaces. When the intraluminal solution had a very low sodium concentration, the mucosa became positive with respect to the serosa; however, over the entire range of sodium concentrations encountered physiologically in bile, the mucosal surface was negative with respect to the serosal surface.

Potassium concentration in the mucosal solution at equilibrium. The experiments cited indicated that the magnitude and sign of the potential difference across the gallbladder epithelium varied with the sodium concentration in the mucosal solution. If the distribution of potassium across the gallbladder epithelium were influenced by these potential differences, then the potassium concentration in the mucosal solution at equilibrium should also vary with the mucosal sodium concentration.

To test this hypothesis a series of cannulated in vivo gallbladders was filled with measured volumes of isosmotic sulfate test solutions of varying sodium concentrations but a constant potassium level of $3.5 \mathrm{mEq}$ per L. After 1 hour each test sample was removed, net volume changes were 


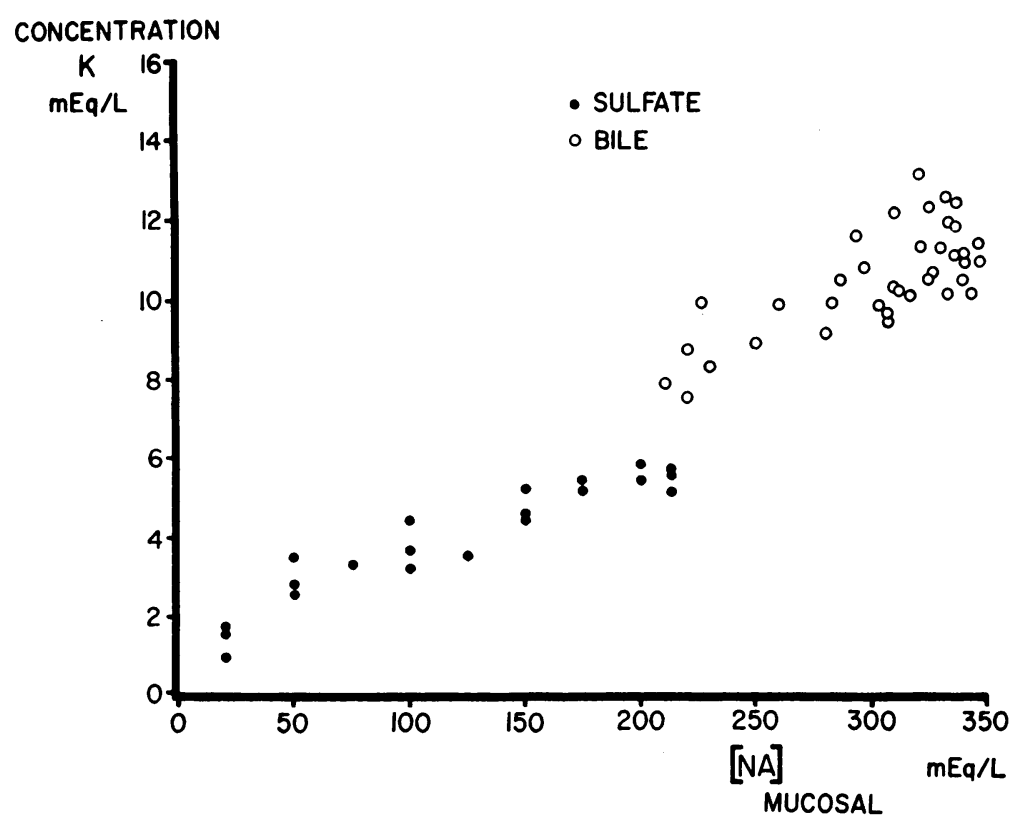

Fig. 4. Potassium concentration in the gallbladder contents at EQUILIBRIUM. The solid circles represent the potassium concentrations reached in sulfate test solutions placed in the in vivo gallbladder for 1 hour plotted against the sodium concentration in each test solution. The open circles are the equilibrated potassium concentrations in bile samples plotted against the bile sodium concentration.

noted, and potassium concentrations were determined. Because the test solutions contained sulfate and mannitol, neither of which readily penetrates the epithelial membrane, no net electrolyte or water absorption occurred from the gallbladder during the test period. Hence, after 1 hour the volume of the test solution either remained unchanged or increased by a slight amount (up to $5 \%$ of the original volume). The potassium concentration shifted up or down from the initial value of $3.5 \mathrm{mEq}$ per $\mathrm{L}$ depending upon the sodium concentration (and hence the potential of the mucosa) in the test solution. Such changes usually occurred within 30 minutes, but the test period was prolonged to 1 hour to make certain that potassium equilibration across the epithelial surface was complete. The solid circles in Figure 4 show the concentration of potassium achieved at equilibrium in each mucosal solution plotted against the test solution sodium concentration. In samples containing only $20 \mathrm{mEq}$ per L of sodium, potassium concentrations dropped to 0.9 to $1.7 \mathrm{mEq}$ per L. The potassium level rose as the sodium concentration in the test solution was in- creased and reached 5.2 to $6.0 \mathrm{mEq}$ per $\mathrm{L}$ when the mucosal sodium concentration was $220 \mathrm{mEq}$ per L.

Similar experiments were done to demonstrate that the same phenomenon occurred when the in vivo gallbladder was filled with whole bile. The open circles in Figure 4 represent the equilibrated potassium concentration plotted against the sodium concentration in 37 bile samples. The same trend is apparent; the higher the sodium concentration (and the more negative the mucosa), the higher is the potassium concentration at equilibrium. Direct potential difference measurements during these equilibration experiments were not possible, since the salt bridges leaked potassium into the test solutions.

Calculated potassium activities at equilibrium. If potassium distribution across the in vivo gallbladder wall is dictated solely by passive transport phenomena, then at $37^{\circ} \mathrm{C}$ the following form of the Nernst equation should apply (6): $E=$ $61.5 \cdot \log (\mathrm{K}$ activity in serum $) /(\mathrm{K}$ activity in gallbladder). Since the volume of the blood is very large compared to the volume of the solution 


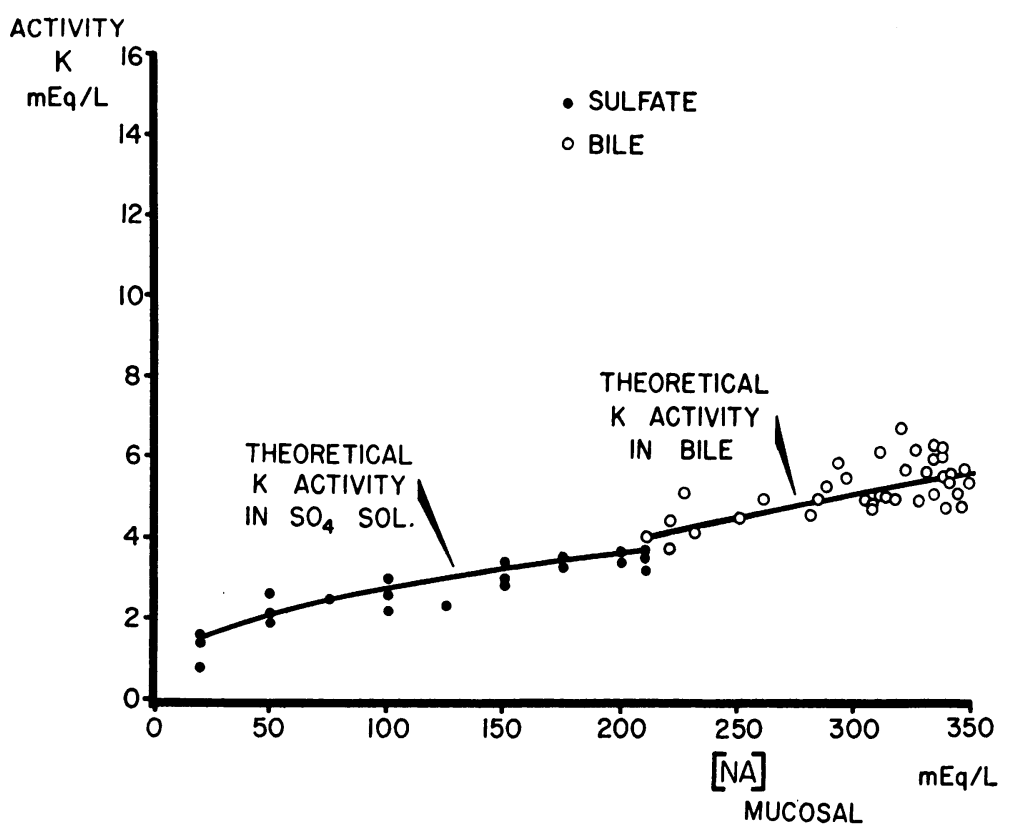

Fig. 5. ObServed potassium aCtivity at equilibrium Plotted against THE SODIUM CONCENTRATION IN THE SULFATE TEST SOLUTION OR BILE SAMPLE. The theoretical activity curves for the sulfate test solutions and for bile samples were derived from the Nernst equation as described in the text.

contained within the gallbladder, any changes in the ratio ( $\mathrm{K}$ activity in serum) $/(\mathrm{K}$ activity in gallbladder), induced by a potential difference (E), will be reflected by changes in the potassium activity in the gallbladder contents while the serum potassium activity remains constant. In blood samples taken from ten rabbits during the experimental periods the mean serum potassium concentration was $3.9 \pm 0.4 \mathrm{mEq}$ per L. Since the activity coefficient of potassium at this concentration in the presence of the other electrolytes in serum is about 0.75 (2), this corresponds to a mean serum potassium activity of $2.9 \pm 0.3 \mathrm{mEq}$ per $\mathrm{L}$.

For any particular sodium concentration in a bile sample or sulfate test solution placed in the in vivo gallbladder the expected potential difference across the gallbladder wall can be obtained from the mean experimental curves in Figure 2 and Figure 3, respectively. With the values of the potential difference and the mean serum potassium activity known, the Nernst equation can be used to calculate the expected potassium activity in the gallbladder contents at equilibrium. For example, when a solution containing $20 \mathrm{mEq}$ per $\mathrm{L}$ of $\mathrm{Na}_{2} \mathrm{SO}_{4}$ is placed in the gallbladder, the mu- cosa is about $14.3 \mathrm{mv}$ positive to the serosa (Figure 3 ). The calculated potassium activity in this mucosal test solution at equilibrium is $1.7 \mathrm{mEq}$ per L. For a bile sample with a sodium concentration of $300 \mathrm{mEq}$ per $\mathrm{L}$ the expected potential is about $-16.0 \mathrm{mv}$ (Figure 2), and the calculated potassium activity in the bile at equilibrium is $\mathbf{5 . 3}$ $\mathrm{mEq}$ per L. One can calculate the expected potassium activities over the entire range of sodium concentrations in the sulfate test solutions or bile samples; such calculations give the two theoretical curves shown in Figure 5.

Experimental potassium activities at equilibrium. The data in Figure 4 show the experimentally determined potassium concentrations found in the gallbladder contents at equilibrium. To compare these individual points to the theoretical curves in Figure 5 each potassium concentration value must be converted to potassium activity. This requires knowledge of the activity coefficients of potassium in the presence of varying concentrations of sodium, sulfate, and bile acid ions. Such data have been determined by means of selective sodium and potassium glass electrodes for sodium and potassium sulfate solutions, as 
well as for solutions of the sodium and potassium salts of a variety of free and conjugated bile acids (2).

From the data thus obtained it is possible to approximate activity coefficients in mixed solutions of sodium and potassium sulfate and of sodium and potassium deoxycholate (Figure 6). For example, in a solution containing $5 \mathrm{mEq}$ per $\mathrm{L}$ of $\mathrm{K}_{2} \mathrm{SO}_{4}$ and $150 \mathrm{mEq}$ per $\mathrm{L}$ of $\mathrm{Na}_{2} \mathrm{SO}_{4}$, the activity coefficient for the potassium ion is about 0.647 . In a similar solution of $5 \mathrm{mEq}$ per $\mathrm{L}$ of potassium deoxycholate and $150 \mathrm{mEq}$ per $\mathrm{L}$ of sodium deoxycholate, the activity coefficient of the potassium ion is about 0.539 . These, of course, are activity coefficients measured in pure solutions. In the sulfate test solutions left in the in vivo gallbladder for 1 hour other ions such as chloride and bicarbonate enter the solutions, causing some deviation from these predicted activity coefficients. However, the deviation should be small, since these ions are present in relatively low concentrations. Concentrated rabbit bile also contains small amounts of calcium, chloride, bicarbonate, and other ions; however, the concentration of these substances is also low compared to sodium and bile acid ions.

The predominant bile acid present in rabbit bile is the glycine conjugate of deoxycholic acid (7). Since activity coefficient values do not appear to be affected by conjugation (2), potassium activity coefficients in rabbit whole bile are approximated by values obtained in pure deoxycholate solutions. Thus, in the conversion of the observed potassium concentration values (Figure 4) to appropriate activity values each bile sample was considered a pure mixture of sodium and potassium deoxycholate, and activities were calculated by using the activity coefficients presented in Figure 6. Similarly, each sulfate test solution was considered a pure mixture of sodium and potassium sulfate, and the conversion of potassium concentration at equilibrium to potassium activity was effected by the use of the appropriate activity coefficient from Figure 6.

The resulting "observed" potassium activities in sulfate test solutions and in 37 native bile samples are plotted in Figure 5. There is close correlation between these observed potassium activities and the calculated values (solid lines) predicted
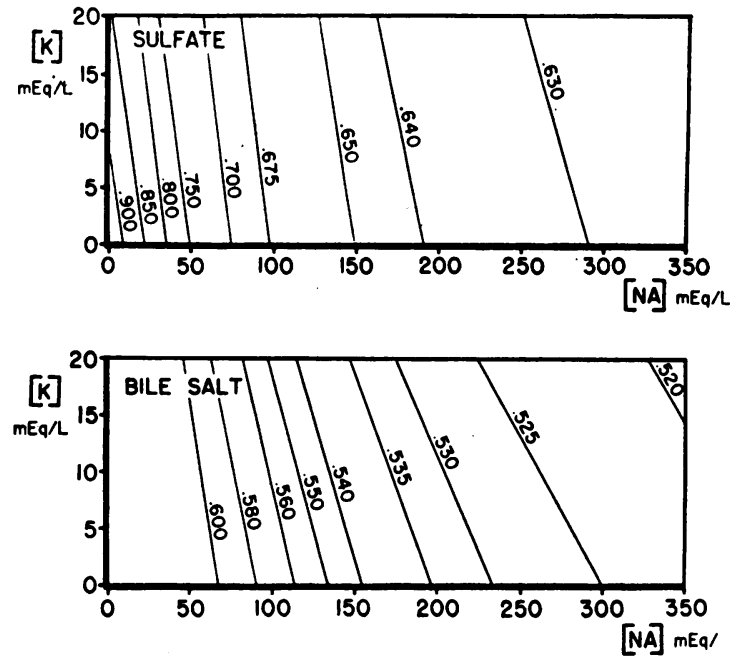

Fig. 6. Activity coefficients of Potassium in MIXED SOLUTIONS OF SODIUM AND POTASSIUM SULFATE AND IN SODIUM AND POTASSIUM DEOXYCholate (BILE SALT). For a particular ionic mixture, project lines perpendicular to the ordinate and abscissa from the appropriate concentrations; the point of interception of the two lines gives the activity coefficient for potassium in the mixed solution (2).

from the Nernst equation. The data indicate that over a wide range of potential differences across the gallbladder wall potassium becomes distributed between bile and serum according to existing electrochemical gradients.

\section{Discussion}

These experiments demonstrate the relationship between the transmucosal potential difference in the gallbladder and the bile potassium concentration. Although not specifically investigated in the present study, enough information is now available concerning ion movement in the gallbladder to allow speculation as to the source of this potential difference. At least three phenomena may result in electrical potentials across biologic membranes: 1) active ion transport across the membrane (transport potentials), 2) transmembrane osmotic gradients (streaming potentials), and 3) transmembrane ionic activity gradients (diffusion potentials). It is unlikely that either of the first two possibilities, i.e., transport or streaming potentials, accounts for the potential differences measured in these experiments. Although the gallbladder epithelium actively transports sodium, unlike many other epithelial sur- 
faces it develops essentially no transport potential. For example, the fish (1) and everted rabbit gallbladder (8) transport electrolytes, but when bathed on both surfaces with identical physiologic solutions only a few millivolts potential difference develops across the epithelial surface. This observation apparently is explained by interdependent transport of sodium and anions resulting in a "neutral" pump mechanism (1). Furthermore, iodoacetate, which is known to stop active solute transport in the gallbladder $(1,8)$, does not alter the magnitude of the potential differences measured in in vitro gallbladders in this study. Streaming potentials have been measured across the isolated gallbladder when water movement is induced by large osmotic gradients across the epithelial surface $(8,9)$. In the present study, how- ever, no such gradients existed, since all test solutions were kept isosmotic with blood.

In the various experimental situations large differences in ionic composition usually existed between the sulfate test solutions or whole bile bathing the mucosal surface of the gallbladder and the Tyrode's solution or animal's blood perfusing the serosal surface. These transmembrane ionic activity gradients undoubtedly result in the production of diffusion potentials that probably account for the potential differences which were measured in the present study. If this is true, the Hodgkin-Katz equation (10) should predict the magnitude of the potential difference (6). With the major univalent ions in serum, bile, and the sulfate test solutions considered, the equation takes the following form at $37^{\circ} \mathrm{C}$ (1):

$$
\mathrm{E}=61.5 \cdot \log \frac{(\mathrm{Na})_{\mathbf{s}}\left(\gamma_{\mathrm{Na}}\right)\left(\mathrm{P}_{\mathrm{Na}}\right)+(\mathrm{K})_{\mathbf{s}}\left(\gamma_{\mathrm{K}}\right)\left(\mathrm{P}_{\mathrm{K}}\right)+(\mathrm{Cl})_{\mathrm{m}}\left(\gamma_{\mathrm{Cl}}\right)\left(\mathrm{P}_{\mathrm{Cl}}\right)+(\mathrm{BS})_{\mathrm{m}}\left(\gamma_{\mathrm{BS}}\right)\left(\mathrm{P}_{\mathrm{BS}}\right)}{(\mathrm{Na})_{\mathrm{m}}\left(\gamma_{\mathrm{Na}}\right)\left(\mathrm{P}_{\mathrm{Na}}\right)+(\mathrm{K})_{\mathrm{m}}\left(\gamma_{\mathrm{K}}\right)\left(\mathrm{P}_{\mathrm{K}}\right)+(\mathrm{Cl})_{\mathrm{s}}\left(\gamma_{\mathrm{Cl}}\right)\left(\mathrm{P}_{\mathrm{Cl}}\right)+(\mathrm{BS})_{\mathrm{s}}\left(\gamma_{\mathrm{BS}}\right)\left(\mathrm{P}_{\mathrm{BS}}\right)}
$$

where $\mathrm{E}$ is the potential difference; (ion) $)_{\mathbf{s}}$ and (ion) $)_{m}$ refer to ionic concentration of the serosal and mucosal fluid, respectively; (BS) represents bile salt; $(\gamma)$ is the activity coefficient of the ion in its respective solution; and $(\mathrm{P})$ is the permeability constant for each ion relative to sodium.
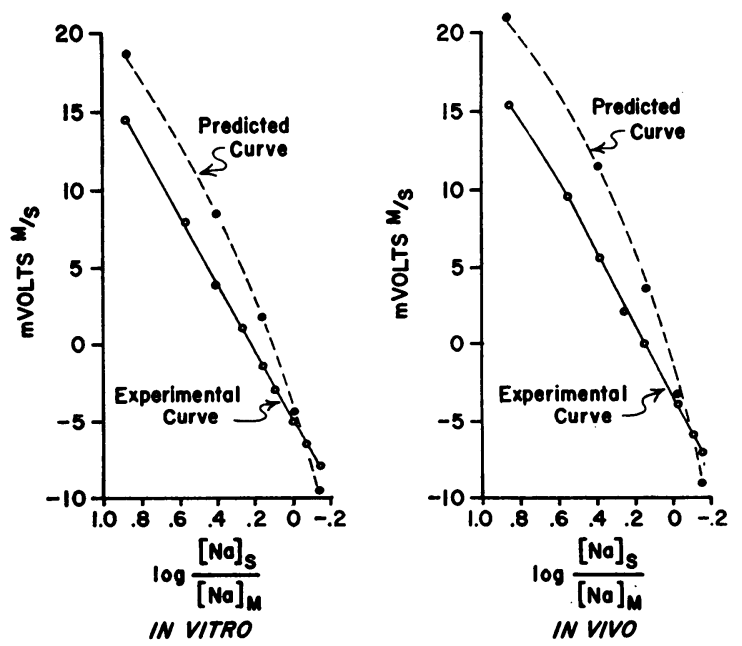

Fig. 7. Potential differences across the wall of THE GALLBLADDER FILLED WITH SULFATE TEST SOLUTIONS. The potential difference is plotted against the log of the ratio of the serosal to mucosal sodium concentration. See legend to Table I for details of the calculation of the predicted curves.
The relative permeability constants in the rabbit gallbladder have been determined (8), and for $\mathrm{Na}^{+}: \mathrm{K}^{+}: \mathrm{Cl}^{-}: \mathrm{BS}^{-}$they equal $1.00: 1.50: 0.33$ : 0.00 .

A comparison of the potential differences found experimentally and those calculated from the Hodgkin-Katz equation is shown in Figure 7 and Table I. The data in Figure 7 demonstrate the close agreement between the measured and theoretical potential differences in in vitro and in vivo gallbladders filled with sulfate test solutions. Actually the correlation between these two sets of curves is probably even closer than shown in Figure 7 because, for the purpose of calculation, the gallbladder mucosa was considered to be completely impermeable to sulfate ion, i.e., in the Hodgkin-Katz equation $\mathrm{P}_{\mathrm{SO}_{4}}$ was considered equal to zero. This assumption is not strictly true for in the rabbit sulfate ion does penetrate the gallbladder epithelium to a limited degree (8). ${ }^{3}$ Because of this sulfate "leak," the magnitude of the

${ }^{3}$ When the rabbit gallbladder is perfused on both surfaces by sodium sulfate solution, a slope of only 50.0 mv rather than $61.5 \mathrm{mv}$ (at $37^{\circ} \mathrm{C}$ ) is obtained for a tenfold change in sodium activity; thus, in contrast to the fish, the rabbit gallbladder does not behave in this situation as a sodium electrode, but, rather, sulfate ion must penetrate the mucosal surface to some degree, 
calculated potentials would be lower so that in Figure 7 the predicted curves would even more closely approximate the experimental curves. In Table I the comparison is made for in vivo and in vitro gallbladders filled with whole bile. Here again there is close agreement between the potential difference measured experimentally across the gallbladder wall and the magnitude of the diffusion potentials calculated from the Hodgkin-Katz equation. These data strongly suggest that ionic activity gradients with consequent diffusion potentials are the principal source of the potential differences measured in the present study.

As bile becomes progressively concentrated, its sodium concentration rises to around $300 \mathrm{mEq}$ per $\mathrm{L}$, and its chloride concentration drops to levels as low as 5 to $10 \mathrm{mEq}$ per L. Thus, in the in situ gallbladder the largest activity gradients between serum and bile are for sodium (about 100 $\mathrm{mEq}$ per L) and for chloride (about $70 \mathrm{mEq}$ per L). Since the epithelial surface is relatively permeable to both of these ions, both significantly influence the magnitude of the potential difference. Other ions in serum and bile are either present in such relatively low concentrations on both sides of the membrane or else have such low permeability constants, e.g., the divalent ions and bile salt, that they contribute only slightly or not at all to the voltage difference between the mucosal and serosal surfaces.

In these experiments, over a wide range of potential differences, potassium distribution between serum and bile was always predictable from the Nernst equation. This suggests passive transport of the ion secondary to electrochemical forces. In no instance did potassium move against an electrochemical gradient so that there was no evidence of an active "secretory" mechanism for this ion. This observation is supported by the recent report of Wheeler (11) that the flux ratio for potassium ion across the rabbit gallbladder wall is consistent with passive diffusion of the ion.

The sequence of events that occurs in the gallbladder during the process of concentration of bile may be outlined as follows. Newly formed hepatic bile is delivered into the gallbladder as an isosmotic solution with sodium the principal cation and chloride, bicarbonate, and bile acids the principal anions. Active solute absorption by the gall-
TABLE I

Potential differences across the wall of the bile-filled gallbladder*

\begin{tabular}{ccccccc}
\hline & \multicolumn{3}{c}{ Bile composition } & & \multicolumn{2}{c}{ Mucosal potential } \\
\cline { 2 - 4 } \cline { 5 - 6 } In vitro & $\mathrm{Na}$ & $\mathrm{K}$ & $\mathrm{Cl}$ & & Measured & Calculated \\
& & $m E q / L$ & & & \\
& 189 & 8.5 & 37 & & -8.7 & -7.4 \\
& 216 & 11.0 & 21 & & -10.0 & -11.5 \\
& 280 & 12.1 & 9 & & -16.2 & -16.5 \\
In vivo & 321 & 13.9 & 5 & & -18.9 & -19.7 \\
& 260 & 8.0 & 40 & & -14.1 & -12.3 \\
& 325 & 12.1 & 10 & & -18.2 & -19.1 \\
& 300 & 9.2 & 12 & -16.1 & -16.6 \\
& 340 & 13.4 & 5 & -19.8 & -20.4
\end{tabular}

* These data compare the potential differences measured across the wall of the in vitro and in vivo gallbladders filled with whole bile and those calculated from the Hodgkin-Katz equation. For these calculathose calculated from the Hodgkin-Katz equation. For these calculations the relative permeability constants used were $1.00: 1.50: 0.33: 0.00$ for $\mathrm{Na}^{+}: \mathrm{K}^{+}: \mathrm{Cl}^{-}: \mathrm{BS}^{-}$. Cationic activity coefficients $\left(\gamma^{+}\right)$were determined with glass electrodes (2); the values used for $\gamma_{\mathrm{N}}{ }^{+}$in Tyrode' solution and rabbit blood were 0.755 and 0.750 , respectively; $\gamma_{\mathrm{Na}}{ }^{+}$in whole bile varied from 0.60 to $0.67 . \gamma \mathrm{Cl}^{-}$and $\gamma \mathrm{K}^{+}$were considered equa to the value of $\gamma_{\mathrm{Na}}{ }^{+}$in Tyrode's solution and blood, but in whole bile, the potassium activity coefficient varied from 0.45 to 0.55 .

bladder epithelium decreases the chloride and bicarbonate concentration and raises the level of sodium bile salt to about $300 \mathrm{mEq}$ per $\mathrm{L}$. Ionic activity gradients between serum and bile, principally for sodium and chloride, cause the mucosa to become 16 to $19 \mathrm{mv}$ negative to the serosa. Because of this electrical gradient, the activity of potassium in bile must be about twice as high as in serum, if this passively transported ion is to remain in electrochemical equilibrium across the gallbladder epithelium. Because the activity coefficient of potassium in whole bile is lower than the activity coefficient of potassium in serum the bile potassium concentration is about three times that of the serum.

\section{Summary}

During the process of bile concentration by the rabbit gallbladder, the potassium concentration increases from 4 to $5 \mathrm{mEq}$ per $\mathrm{L}$ in newly formed hepatic bile to 10 to $14 \mathrm{mEq}$ per $\mathrm{L}$ in concentrated gallbladder bile. This increase in potassium concentration has been assumed to represent "secretion" of potassium ions by gallbladder epithelium or a Donnan effect produced by nondiffusible bile acid ions. The purpose of this study was to determine whether this bile-serum concentration gradient for potassium could be explained by electrical potentials across the membrane. Potential differences were measured across in vivo 
and in vitro rabbit gallbladders and were found to be directly related to sodium concentration in the mucosal bathing solution. Theoretical bileserum potassium distribution was then calculated from the Nernst equation. Potassium activities in sulphate test solutions and bile were estimated from previously derived activity coefficients determined by sodium- and potassium-selective glass electrodes. A close correlation was found between observed potassium activities and those predicted by the Nernst equation according to existing electrochemical gradients. There was no evidence of an active "secretory" process. The data suggest that the high potassium levels in concentrated gallbladder bile result from passive transport phenomena.

\section{Acknowledgment}

We thank Dr. Franz J. Ingelfinger for his helpful suggestions and comments during the course of these experiments and the preparation of the manuscript.

\section{References}

1. Diamond, J. M. The mechanism of solute transport by the gall-bladder. J. Physiol. (Lond.) 1962, $161,474$.
2. Moore, E. W., and J. M. Dietschy. $\mathrm{Na}$ and $\mathrm{K}$ activity coefficients in bile and bile salts determined with glass electrodes. Amer. J. Physiol., in press.

3. Herman, R. H., T. H. Wilson, and L. Kazyak. Electrolyte migrations across the wall of the guinea pig gall bladder. J. cell. comp. Physiol. 1958, 51, 133.

4. Sobotka, H. Physiological Chemistry of the Bile. Baltimore, Williams \& Wilkins, 1937.

5. Moore, E. W., and D. W. Wilson. The determination of sodium in body fluids by the glass electrode. J. clin. Invest. 1963, 42, 293.

6. Ussing, H. H. The Alkali Metal Ions in Biology. Berlin, Springer-Verlag, 1960.

7. Haslewood, G. A. D., and U. Wootton. Comparative studies of "bile salts," I. Preliminary survey. Biochem. J. 1950, 47, 584.

8. Dietschy, J. M. Water and solute movement across the wall of the everted rabbit gallbladder. Gastroenterology, in press.

9. Diamond, J. M. The mechanism of water transport by the gall-bladder. J. Physiol. (Lond.) 1962, 161, 503.

10. Hodgkin, A. L., and B. Katz. The effect of sodium ions on the electrical activity of the giant axon of the squid. J. Physiol. (Lond.) 1949, 108, 37.

11. Wheeler, H. O. Transport of electrolytes and water across wall of the rabbit gall bladder. Amer. J. Physiol. 1963, 205, 427. 